\title{
1 Interaction between Ballasting Agent and Flocs in Ballasted Flocculation for the Removal of Suspended Solids in Water
}

\section{Nurul Syahidah Zafisah ${ }^{\mathrm{a}}$, Wei Lun Anga, ${ }^{\mathrm{a}}{ }^{*}$, Abdul Wahab Mohammad ${ }^{\mathrm{a}, \mathrm{b}}$, Nidal Hilalc, Daniel J. Johnsonc}

${ }^{a}$ Centre for Sustainable Process Technology (CESPRO), Faculty of Engineering and Built

8 Environment, Universiti Kebangsaan Malaysia, 43600 Bangi, Selangor, Malaysia

9 bChemical Engineering Programme, Faculty of Engineering and Built Environment, Universiti

10 Kebangsaan Malaysia, 43600 UKM Bangi, Selangor, Malaysia

11 'Centre for Water Advanced Technologies and Environmental Research (CWATER), College of

12 Engineering, Swansea University, Singleton Park, Swansea SA2 8PP, UK.

14 *Corresponding author: wl_ang@ukm.edu.my

\section{Abstract}

The interaction between ballasted agent and flocs formed from coagulation/flocculation process is not well understood. This study sought to understand the interaction between ballasted agent and flocs by investigating the impact of ballasted agent on the flocs formation and subsequently the removal of suspended solids in water. Ballasted flocculation was conducted using jar tests where the dosage of flocculant and sand was varied at 1-4 $\mathrm{mg} / \mathrm{L}$ and 2-8 $\mathrm{g} / \mathrm{L}$, respectively. The turbidity removal peaked (90\%) at $2 \mathrm{mg} / \mathrm{L}$ of flocculant and $1 \mathrm{~g} / \mathrm{L}$ of sand. It was observed that excessive

24 dosing of sand resulted in the formation of premature flocs that settled quickly before having the

25 chance to remove more suspended solids via sweep coagulation. This revealed that the ballasted 26 agent would affect the coagulation-flocculation process and subsequently the removal of 27 suspended solids. This study indicates that future research on the impact of the ballasted agent on different coagulation-flocculation mechanism should be explored to ensure the suspended solids could be removed with short settling time and without compromising the quality of treated water.

30 Keywords: Ballasted flocculation; Coagulation; Flocculation; Natural Organic Matter; Water 31 Treatment 


\section{Highlights}

35 - Coagulation process achieved higher turbidity removal but longer settling time.

36 - Ballasted flocculation accelerated the settling rate and formation of large flocs.

37 - Ballasting agent affected the flocs formation during sweep coagulation mechanism.

38 - Quick settling of flocs resulted in the slightly lower removal of suspended solids.

39 - The interaction between the ballasted agent and flocs formation is worth exploring.

40

\section{Introduction}

42

The issue of water scarcity is already a reality to more than 2 billion people, especially with growing populations and increasing water usage [1]. Natural organic matter (NOM) and suspended impurities are compromising with the clarity of water known as turbidity, and settling to the bottom and forming sludge beds [2]. Among numerous water and wastewater treatment technologies, coagulationflocculation process is indisputably the most widely employed technology in water treatment plants [3], [4]. Coagulation-flocculation may be broadly described as the physicochemical process that injects coagulant to destabilize the particles prior to flocculant chemicals to form larger and heavier particle aggregates (flocs) that will settle rapidly for removal by subsequent clarification process [5]-[7].

42 Over the past few decades, land constraint has become one of the major issues in the 43 construction of conventional wastewater treatment plants [8]. Hence, development of ballasted 44 flocculation is of great interest to tackle this issue by reducing the system footprint and hydraulic 45 retention time [9]. Ballasted flocculation involves the injection of a ballasting agent during the 46 flocculation process to increase the size and density of the flocs [10]. Ballasting agent such as 47 microsand typically has a high density that could significantly result in a higher settling velocity 48 compared to non-ballasted flocs [11]. According to previous work done, ballasting agent has 49 greater mass than the microflocs formed during the coagulation-flocculation process, which 50 affecting the size of flocs after the aggregation between the former and the latter and increased 51 settling velocity [12]-[14]. Also, ballasting agent has low surface charge density compared to 
52 colloidal particles in water. Hence, the addition of ballasting agent will not chemically disrupt the

53 interaction between the coagulant/flocculant and colloidal particles [14].

54 Some of the main advantages of ballasted flocculation include reduced system footprint,

55 elevated start-up time, higher settling rate, and minimized usage of coagulant and flocculant [15].

56 Furthermore, the quality of water produced has been reported to be equal to or better than the

57 conventional coagulation-flocculation process [11]. Due to the advantages of the ballasted

58 flocculation process, it was previously employed commercially for drinking water treatment and

59 in recent years, has been further used for combined sewerage overflow (CSO) and wastewater

60 treatment plants [16]. The treatment efficiently reduces hydraulic retention time and increases

61 overflow rate [17]. For instance, ballasted flocculation enhanced water quality and reduced runoff

62 volume from the wastewater treatment plant, which prevented the discharge of nutrients, organic

63 matter and debris into local waterway [8]. As such, it was reported that injecting sand with cationic

64 polymer could provide a higher phosphorus removal efficiency which is the main cause of

65 eutrophication and algal growth in the river [18]. This was possible because ballasted flocculation

66 significantly shortened the time for flocs clarification and sedimentation, allowing the treatment

67 plant to receive more inflow water for treatment.

68 Some of the recent works reported on ballasted flocculation investigated the characteristics

69 of flocs formed under various operating conditions [10], [19], [20]. For instance, Young et. al

70 studied the influence of numerous factors affecting the efficiency of ballasted flocculation

71 separately [14]. Ghanem et. al studied the mechanism of ballasted flocculation through different

72 tests: bench scale observations, microscopic observations, density tests, and centrifugal settling

73 tests [13]. Besides, Sieliechi et. al (2016) used pozzolana as the alternative ballasting agent in their study with attention given to the floc compaction in the presence of ballasting agent [12].

However, reports on the development of fundamental understanding about the interaction between the ballasting agent and polymer flocculant remain scarce. Such understanding could provide insight into the impact of the ballasted agent and polymer flocculant on the characteristics and formation of flocs. In this context, the objective of this study was to investigate the performance of ballasted flocculation in removing turbidity using different dosages of sand and polymer flocculant. Accordingly, the impact of ballasting sand on the coagulation-flocculation mechanism (formation of flocs) was investigated by observing the flocs formed during the ballasted flocculation process. 92 


\section{Materials and methods}

The chemicals used in this study: humic acid, kaolin, ferric chloride $\left(\mathrm{FeCl}_{3}\right)$, calcium chloride $\left(\mathrm{CaCl}_{2} \cdot 2 \mathrm{H}_{2} \mathrm{O}\right)$, sodium bicarbonate $\left(\mathrm{NaHCO}_{3}\right)$, sodium chloride $(\mathrm{NaCl})$, hydrochloric acid

$99(\mathrm{HCl})$ and sodium hydroxide $(\mathrm{NaOH})$ were of analytical grade and purchased from Sigma Aldrich, 100 Malaysia. The polymer-based cationic flocculant (Zetag 8165) with a charge density of 40-50\% 101 was supplied by BASF, Singapore. The characteristics of Zetag 8165 was summarized in Table 1. The ballasting agent used in this study was silica sand with a mean diameter of $75 \mu \mathrm{m}$.

103

104 Table 1

105 Characteristics of Zetag 8165

106

107

2.2 Preparation of synthetic water

108

109

110

111

112

113

114

115

116

117

118

119

Powder

Odourless

Off white

3.5-4.5

All the solutions used in this study were prepared by using ultrapure (UP) water with a quality of $18 \mathrm{M} \Omega \cdot \mathrm{cm}^{-1}$. Humic acid and kaolin were used to represent NOM and suspended solids in water, respectively. The synthetic water was prepared by dissolving $0.1 \mathrm{~g}$ of humic acid powder in $10 \mathrm{ml}$ of $0.1 \mathrm{M} \mathrm{NaOH}$ under continuous stirring for 1 hour. A salt mixture (80 ppm NaCl, 200 ppm $\mathrm{CaCl}_{2} \cdot 2 \mathrm{H}_{2} \mathrm{O}$, and $170 \mathrm{ppm} \mathrm{NaHCO}_{3}$ ) was then added to the humic acid solution to mimic the presence of minerals in the water. Sodium hydrogen carbonate was added to provide carbonate alkalinity similar to that of natural rivers [21]. UP water and kaolin were then added to alter the turbidity to $30 \mathrm{NTU}$. The $\mathrm{pH}$ of the prepared synthetic water was then adjusted to 7 by using $\mathrm{NaOH}$ and $\mathrm{HCl}$. The zeta potential of the synthetic water was $-29.9 \mathrm{mV}$.

\subsection{Ballasted flocculation process}


All experiments were conducted by using a jar test system (Model ZR4-6 Zhongrun Water, 122 China) with $500 \mathrm{ml}$ of prepared synthetic water for each run. The distance between the impeller 123 and the bottom jar is $1 \mathrm{~cm}$ with total water depth of $7 \mathrm{~cm}$. All experiments were repeated twice.

124 Two control sets of coagulation processes: coagulation without flocculant and sand, and 125 coagulation with flocculant but without sand, were carried out to provide benchmarking 126 information for understanding ballasted flocculation process. The jar test setting for coagulation 127 without sand and flocculant was rapid mixing at $100 \mathrm{rpm}$ for $1 \mathrm{~min}$ and slow stirring at $30 \mathrm{rpm}$ for 12830 min. However, the jar test setting for coagulation with flocculant but without sand and also 129 ballasted flocculation were rapid mixing at $200 \mathrm{rpm}$ for $1 \mathrm{~min}$ and followed by a slow mixing at $13030 \mathrm{rpm}$ for $5 \mathrm{~min}$.

131 The optimal coagulant $\left(\mathrm{FeCl}_{3}\right)$ dosage for all experiments was fixed at $22 \mathrm{mg} / \mathrm{L}$, as 132 determined in the previous study [22]. The dosage of flocculant (Zetag 8165) and sand was varied 133 at 1-4 mg/L and 1-4 g/L, respectively. Coagulant was dosed into the solution instantaneously once 134 the rapid mixing was started, followed by flocculant and sand according to the sequence described 135 by Lapointe \& Barbeau [10]. Pictures of the flocs and time for most of the flocs to settle down 136 when entering the slow mixing period was recorded. After the sedimentation period, the 137 supernatant water was then extracted for turbidity and zeta potential analysis.

\subsection{Analytical methods}

The quality of treated water was measured from the removal of turbidity using 142 Turbidimeter (2100N, HACH, USA). The particle charge before and after the ballasted 143 flocculation processes was evaluated based on the zeta potential value using a Zeta-Sizer (Malvern, 144 UK).

145

\section{6}

147 
In order to investigate the impact of sand as a ballasting agent on the formation of flocs, two control sets of coagulation-flocculation process without the addition of sand were conducted. For the first control experiment (with coagulant only), it has been observed that the flocs were gradually formed during the slow stirring period and grew larger with time (Fig. 1).

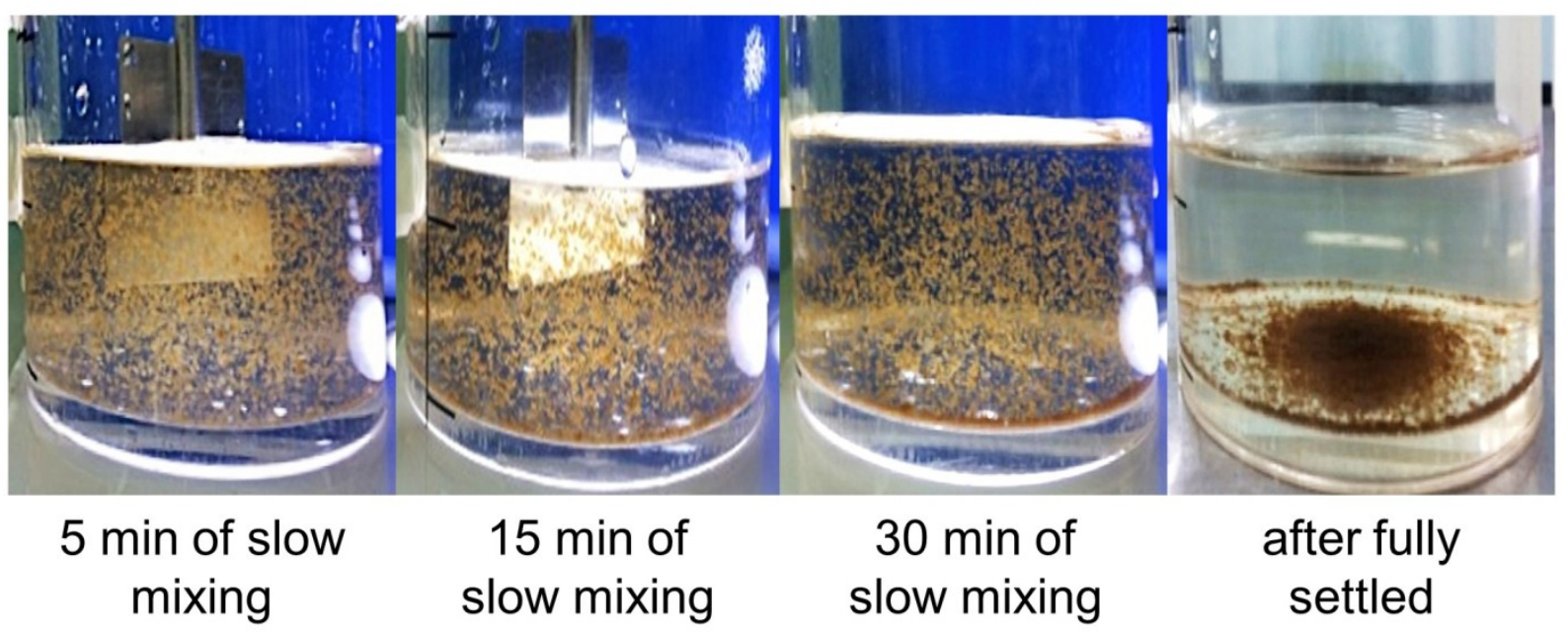

Fig. 1. Development of flocs with coagulant

This observation could be explained by sweep coagulation mechanism as supported by zeta potential value in Table 2. As explained in the previous study, iron-based coagulant hydrolysed to form positively charged ferric hydroxides that partially neutralized the negatively charged particles and bound them together to form flocs [6], [23]. During the slow stirring period, small flocs swept across the solution and captured the residual suspended solids particle. At the same time, the flocs collided with each other and coalesced into larger aggregates, as indicated by the growing size of flocs in Fig. 1. A similar observation was reported by Ang et al. [22] where the flocs became larger and heavier due to collision between positively charged ferric precipitates and negatively charged suspended solids particles through the sweeping mechanism. Both phenomena resulted in the removal of more suspended solids and formation of larger flocs for subsequent removal via sedimentation. The time taken for the majority of the flocs to settle was more than 5 min, as tabulated in Table 2.

In comparison, the addition of flocculant in the second control set reduced the settling time of the flocs to around 2 min with the formation of larger flocs. Fig. 2 shows the development of flocs with the addition of flocculant in the coagulation-flocculation process. It could be observed 
173 that the flocs in Fig. 2 are larger compared to the flocs without flocculant in Fig. 1. This is because 174 the flocculant acted as a binder which bound the suspended flocs together, further increased the 175 entanglement of flocs during the stirring period [24]. Therefore, this resulted in two consequences;

176 lower turbidity removal and shorter settling time. It was postulated that larger flocs had less 177 exposure to residual suspended solids in the solution due to its lower surface area and shorter 178 suspension period in the solution. Hence, the turbidity of the treated water with flocculant (2.36 179 NTU) was subsequently lower compared to without flocculant (0.69 NTU) as presented in Table 1802.

181

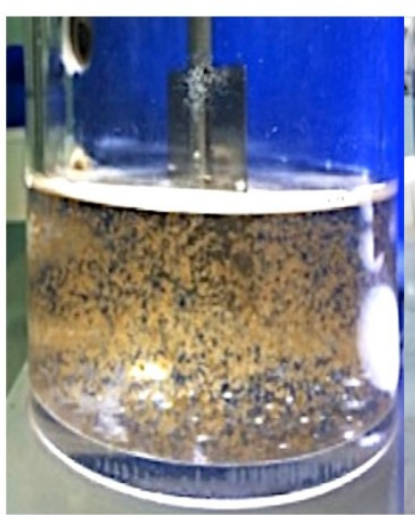

5 min of slow

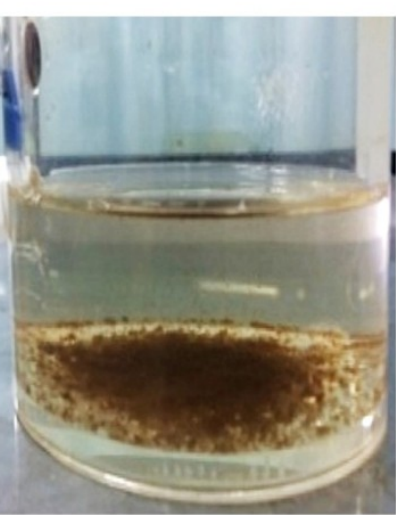

after fully settled

183 Fig. 2. Development of flocs with coagulant and flocculant

Table 2

186 Turbidity and zeta potential of control sets (with coagulant only, with coagulant and flocculant)

\begin{tabular}{llll}
\hline $\begin{array}{l}\text { Synthetic water } \\
\text { condition }\end{array}$ & Settling time (s) & Turbidity (NTU) & Zeta Potential (mV) \\
\hline $\begin{array}{l}\text { With coagulant only } \\
\text { With coagulant and }\end{array}$ & $>300$ & 0.69 & -18.6 \\
flocculant & $>120$ & 2.36 & -18.7 \\
\hline
\end{tabular}


The flocculant used in this study was Zetag 8165, which is a positively charged polymer 190 with zeta potential of $52.43 \mathrm{mV}$ at $\mathrm{pH}$ 7. The success of the coagulation-flocculation process is 191 heavily reliant on the destabilization of the negatively charged suspended solid particles with a 192 high oppositely charged coagulant and flocculant [25]. The cationic polymer flocculant played a 193 significant role in the formation of flocs by destabilizing the repulsion forces between the particles 194 and interacted with the particles to form larger agglomerates [26].

195 Table 3 presents the turbidity of the supernatant under the influence of different flocculant 196 dosage (1-4 mg/L) and sand dosage fixed at $1 \mathrm{~g} / \mathrm{L}$. From Fig. 3, it was observed that the turbidity 197 removal increased from 35\% to $90 \%$ with the dosage of flocculant increased up to $2 \mathrm{mg} / \mathrm{L}$. 198 However, a further increment of flocculant dosage (>2 mg/L) did not help with the removal of 199 turbidity where the removal efficiency declined slightly (1-2 \%). Indeed, as tabulated in Table 3, 200 the final turbidity of the supernatant solution under these dosages are within in the same range (3$2013.5 \mathrm{NTU}$ ). Hence, it could be concluded that the optimal dosage of flocculant in this case was 2 $202 \mathrm{mg} / \mathrm{L}$.

203

204 Table 3

205 Effect of flocculant dosage on settling time, turbidity, and zeta potential

\begin{tabular}{cccc}
\hline $\begin{array}{c}\text { Flocculant } \\
\text { dosage }(\mathrm{mg} / \mathrm{L})\end{array}$ & $\begin{array}{c}\text { Settling } \\
\text { time }(\mathrm{s})\end{array}$ & $\begin{array}{c}\text { Turbidity } \\
(\mathrm{NTU})\end{array}$ & $\begin{array}{c}\text { Zeta } \\
\text { Potential }(\mathrm{mV})\end{array}$ \\
\hline 1 & 4.01 & 19 & -25.9 \\
2 & 3.21 & 3.1 & -21.1 \\
3 & 3.55 & 3.32 & -20.6 \\
4 & 3.86 & 3.41 & -19.9 \\
\hline
\end{tabular}




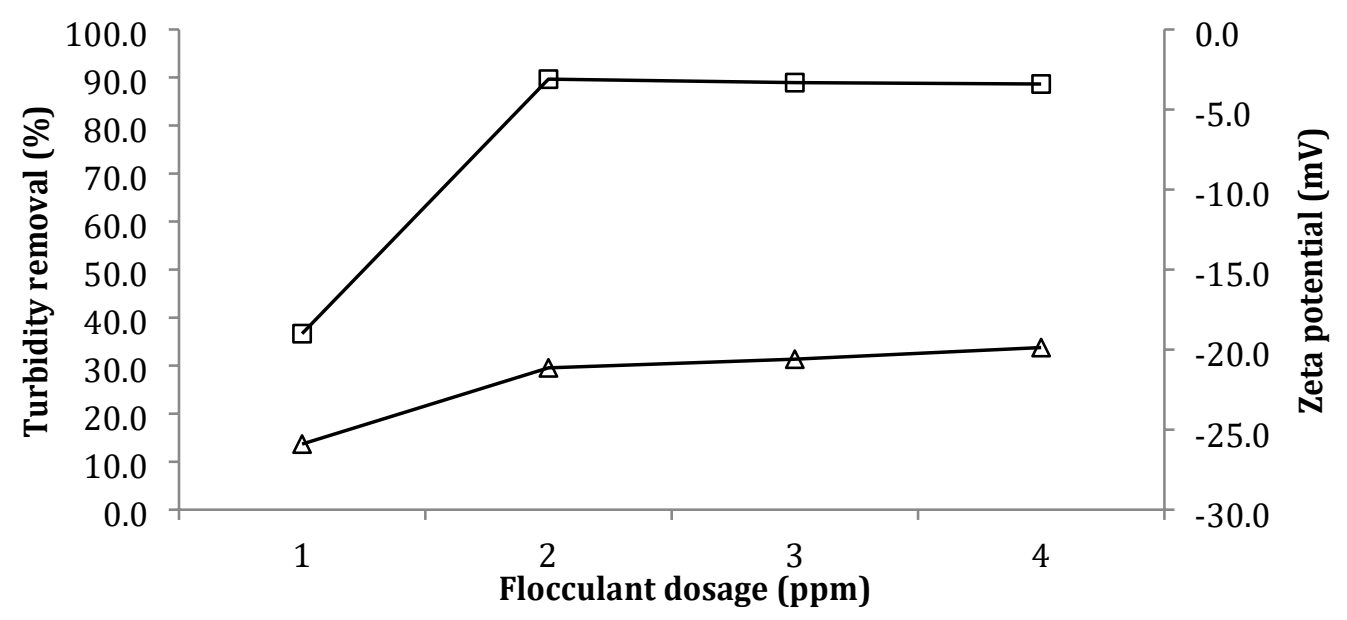

$\square$ Turbidity removal $\triangle$ Zeta potential

Fig. 3. Effect of different flocculant dosage on turbidity removal and zeta potential

Fig. 4 provides direct visual evidence on the quality of the supernatant after ballasted

211 flocculation at different flocculant dosages. It is visible that with $1 \mathrm{mg} / \mathrm{L}$ dosage of flocculant, the

212 supernatant appeared turbid with most of the suspended solids remained in the solution and only

213 small number of flocs settled at the bottom (Fig. 4(a)). On the other hand, the supernatant solutions

214 for flocculant dosage of 2-4 mg/L were much clearer with large flocs settled at the bottom (Fig.

215 4(b)-(d)). Such observation can be explained by the interaction between the flocculant and flocs

216 during the ballasted flocculation process. In this case, the zeta potential was used to understand 217 the interaction between the flocculant and suspended solids particles that eventually can be utilized 218 to explain the observed performance [27].

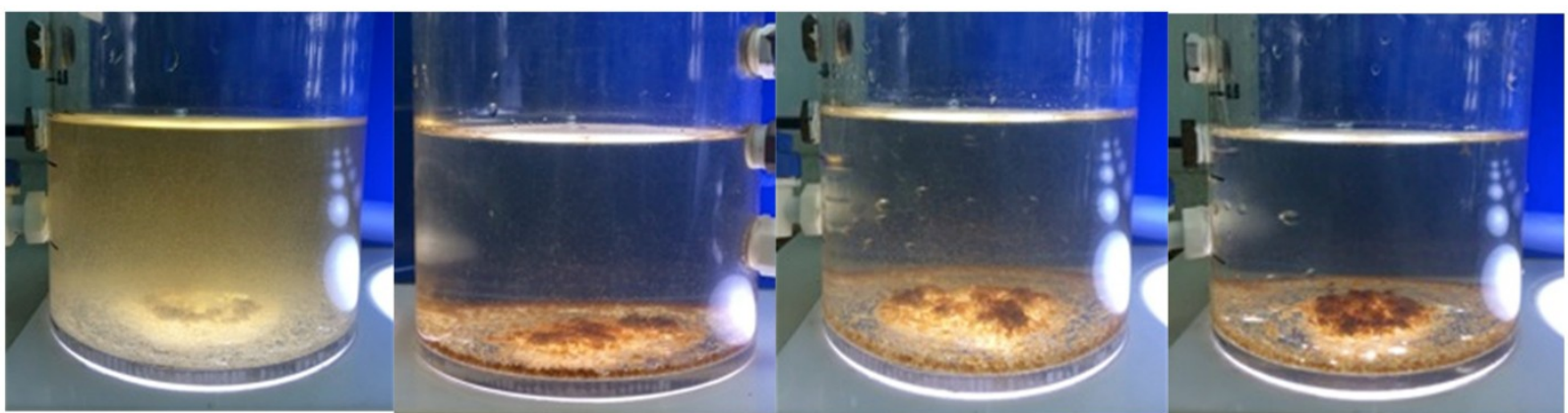

(a)

(b)

(c)

(d)

221 Fig. 4. Floc formations of different flocculant dosage after settling; (a) $1 \mathrm{mg} / \mathrm{L}$ (b) $2 \mathrm{mg} / \mathrm{L}$ (c) 3 $222 \mathrm{mg} / \mathrm{L}(\mathrm{d}) 4 \mathrm{mg} / \mathrm{L}$ 
With the addition of coagulant only (as discussed in the previous section), the zeta potential of the supernatant was around $-18.6 \mathrm{mV}$. After the addition of $1 \mathrm{mg} / \mathrm{L}$ of flocculant and $1 \mathrm{~g} / \mathrm{L}$ of 226 sand, the final zeta potential was $-25.9 \mathrm{mV}$, which was more negative compared to the control set. 227 It could be attributed to insufficient of flocculant dosage to weaken the charge repulsion and bind 228 the particles together [28]. Consequently, most of the suspended solids were still present in the 229 solution and resulted in a turbid supernatant, as shown in Fig. 4(a). Some flocs were formed in this 230 ballasted flocculation process, but the size and amount were obviously smaller and lesser 231 compared to other flocculation scenarios. The settling time for the majority of the flocs was around 2324 seconds, which was not much different from the rest.

233 The zeta potential values for the ballasted flocculation process with dosages $2-4 \mathrm{mg} / \mathrm{L}$ were 234 within the range of $-20 \mathrm{mV}$. The more positively zeta potential charge showed that the cationic 235 polymer flocculant played a role in the formation of flocs by weakening the repulsion charge 236 (negatively charge) on particles and bound the particles together to form larger flocs [26]. The 237 settling time for most of the flocs during the slow mixing period was within 3-4 seconds. It was 238 considerably fast compared to the control sets without flocculant and sand (>300 seconds) and 239 with flocculant only (>120 seconds). The incorporation of sand in the flocs had increased both its 240 size and density, hence reduced its settling time [29]. This reflected the benefit of ballasted 241 flocculation, which can significantly shorten the settling time for flocs sedimentation and 242 clarification. However, the improvement in settling time had compromised the final quality ofthe 243 supernatant, where the final turbidity for ballasted flocculation was around 3 NTU, slightly higher 244 than 1 NTU when only coagulation process was employed. This is because the flocs embedded 245 with sand in ballasted flocculation appeared to be much larger, thus reducing the collision rate 246 with the residual turbidity due to faster settling rate and lesser contact frequency between the flocs. 247 Fig. 4 shows that the size of the flocs grew larger with the flocculant dosage, corresponding well 248 with the postulation where the larger flocs had lesser chance to capture the residual turbidity and 249 resulted in lower turbidity removal.

250 In previous studies, it was reported that $\mathrm{FeCl}_{3}$ coagulation process removed the NOM and 251 suspended solids by sweep coagulation mechanism [6], [30]. Under this mechanism, the coagulant 252 formed high positive charged hydroxides that captured the negative charged impurities. During the 253 slow stirring period, the flocs swept across the solution, grew larger by enmeshing the other flocs, 
254 residual NOM and suspended solids present in the solution. Subsequently, the flocs became 255 heavier due to the incorporation of sand and settled faster during the sedimentation period [10]. 256 This is as in evidence by the large dark brown flocs settled at the bottom in Fig. 4 (b)-(d).

\subsection{Effect of sand dosage} while the sand dosage varied from 1-4 g/L. The incorporation of polymer flocculant assisted the sand to attach to the flocs due to the binding property of the polymer [11]. Fig. 5 shows that the 263 turbidity removal decreased slightly from $90 \%$ to $86 \%$ with the dosage of sand. Such trend was 264 also observed by Sieliechi et al. that a slight deterioration of the residual turbidity was noted with 265 the increased dosage of pozzolana particles as ballasting agent [12].

266 The increased dosage of sand resulted in the formation of smaller, isolated, and heavy flocs. 267 As observed in Fig. 6, the flocs settled at the bottom of the jars shows an interesting pattern. The 268 flocs formed for the sand dosage of 2-4 g/L appeared to be smaller, unlike the flocs in Fig. 6(a), 269 which were in large chunk form. In addition, a greater number of flocs formed at sand dosage 2$2704 \mathrm{~g} / \mathrm{L}$ compared to sand dosage at $1 \mathrm{~g} / \mathrm{L}$, in which the flocs covered larger area of the jars. This 271 observation indicates the role and impact of sand in the formation of flocs that would directly 272 influence the turbidity and suspended solids removal.

273

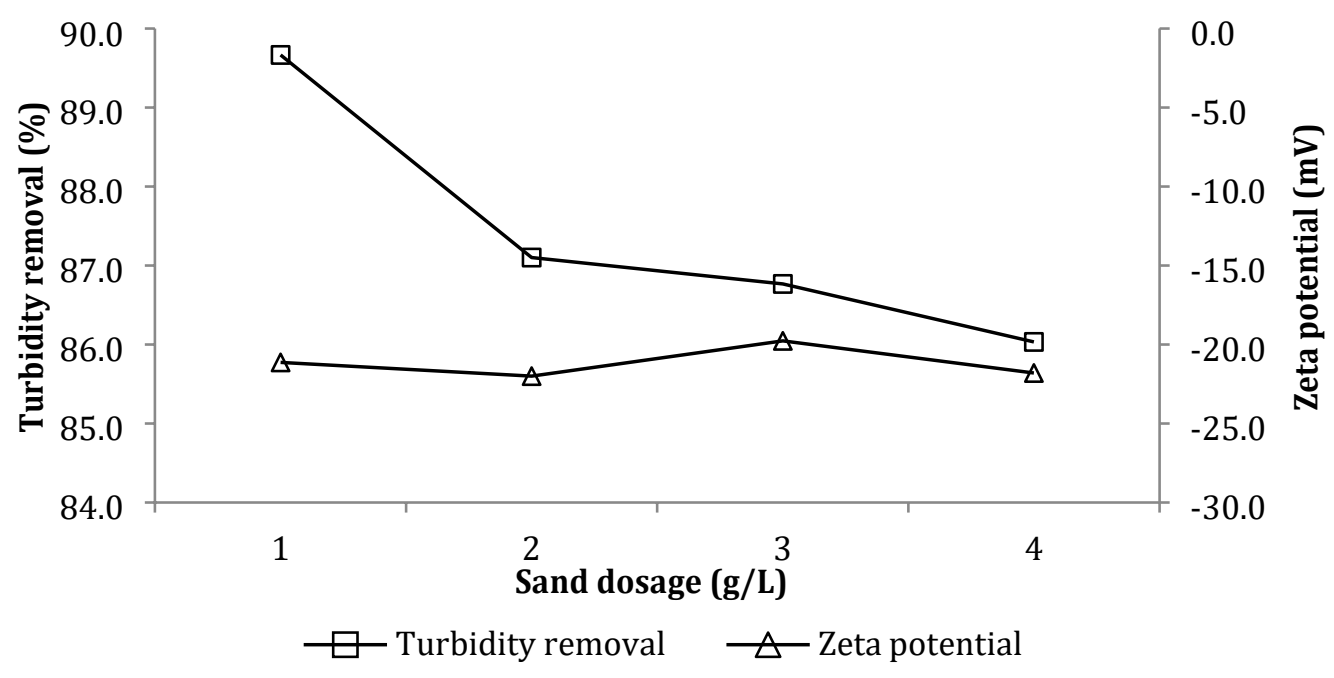

Fig. 5. Effect of different sand dosage on turbidity removal and zeta potential 


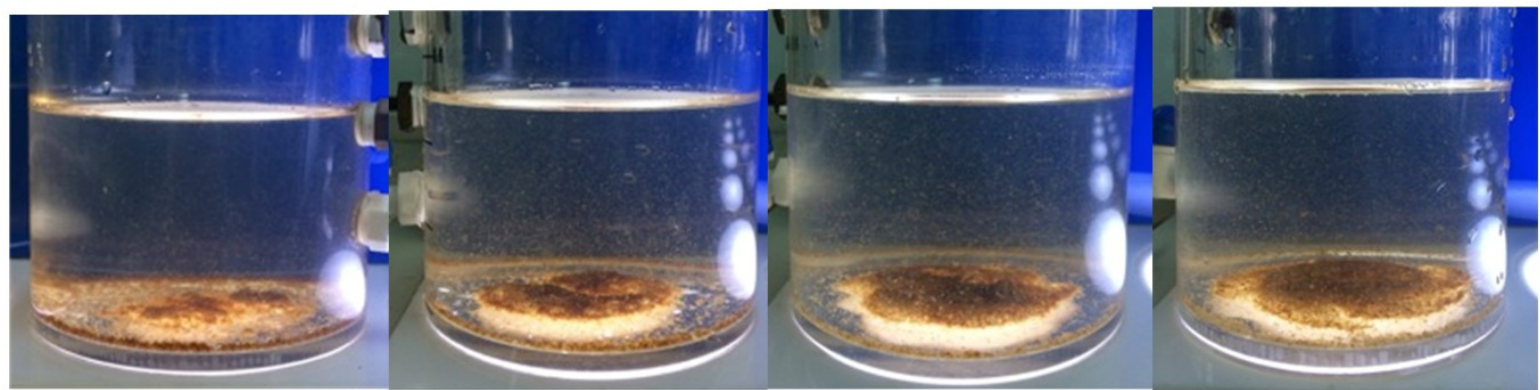

277 (a)

(b)

(c)

(d)

278 Fig. 6. Floc formations of different sand dosage after settling; (a) 1 g/L (b) 2 g/L (c) 3 g/L (d) 4 $279 \mathrm{~g} / \mathrm{L}$

Table 4

282 Effect of sand dosage on settling time, turbidity, and zeta potential

\begin{tabular}{|c|c|c|c|}
\hline $\begin{array}{l}\text { Sand dosage } \\
(\mathrm{g} / \mathrm{L})\end{array}$ & Settling time (s) & Turbidity (NTU) & Zeta Potential $(\mathrm{mV})$ \\
\hline 0 & - & 30 & -29.9 \\
\hline 1 & 3.21 & 3.1 & -21.1 \\
\hline 2 & 3.37 & 3.87 & -22.0 \\
\hline 3 & 3.81 & 3.97 & -19.8 \\
\hline 4 & 4.73 & 4.19 & -21.8 \\
\hline
\end{tabular}

Table 4 presents the zeta potential of the supernatant solution after the ballasted 285 flocculation process. Generally, the zeta potential values fall in the same range regardless of the 286 sand dosage. The result revealed that sand has no chemical interaction with the coagulant or 287 flocculant as mentioned by Young et al. [14]. Instead, sand interacted physically with the flocs and 288 resulted in the formation of flocs with a marked difference in size and quantity for the various 289 dosage of sand. From the preliminary study, sand could not be embedded into the flocs without 290 the dosing of flocculant. It was due to the binding property of flocculant that the sand could be 291 incorporated into the flocs [11].

292 Based on the zeta potential value in Table 4, it could be deduced that sweep coagulation 293 was the main mechanism for the removal of turbidity and suspended solids. This mechanism 
294 utilizes the presence of premature flocs to sweep across the solution and captures more impurities 295 before settling down for subsequent removal [22]. The aggregation of larger flocs from premature 296 flocs was due to van der Waals attraction that facilitated the sweep coagulation mechanism [31]. 297 The addition of excessive sand $(>1 \mathrm{~g} / \mathrm{L})$ increased the presence of sand in the solution and 298 thus enabled more sand to be embedded into the premature flocs. These flocs were small yet heavy 299 due to the incorporation of sand. Consequently, the flocs tended to settle quickly, especially during 300 the slow mixing period. With the diminishing of suspended flocs to sweep across the solution, the 301 removal of residual particles was also reduced. Furthermore, the premature flocs also had lesser 302 chance to collide with each other to form larger flocs as shown in Fig. 6(a). This is in good 303 agreement with the result reported by Gasperi et al. that the addition of excessive sand dosage 304 saturated the flocs and reduced particulate removal [17]. Hence, this explained the increased in 305 final turbidity of the supernatant with sand dosage more than $1 \mathrm{~g} / \mathrm{L}$.

306 The settling time for the flocs is reported in Table 4. The settling time did not record any 307 significant difference for all sand dosages. The slightly longer settling time (4.73 s) with $4 \mathrm{~g} / \mathrm{L}$ of 308 sand could be attributed to the remaining light premature flocs that did not have the chance to 309 embed with the sand or collide with other flocs to form heavy agglomerates. Nonetheless, the time 310 difference was too small to have any significant impact.

311 Overall, this study shows that the incorporation of ballasting agent has the potential to 312 interrupt the efficiency of existing water and wastewater treatment (coagulation/flocculation) 313 process. It was also noticeable that sweep coagulation mechanism required the flocs to sweep 314 across the solution for a longer period in order to capture more suspended solid particles. The 315 addition of sand increased the density of the flocs significantly and rapidly settled the flocs. With 316 fewer flocs available to sweep across the solution, removal of impurities also declined. This 317 indicated that the interaction between the ballasting agent and flocs should be considered during 318 the design of ballasted flocculation process.

\section{Conclusion}

The results presented in this study provided understanding about the interaction between 323 sand and flocs in the ballasted flocculation process. The optimal dosage for this study was $2 \mathrm{mg} / \mathrm{L}$ 324 of flocculant and $1 \mathrm{~g} / \mathrm{L}$ of sand that gave rise to $90 \%$ of turbidity removal. The settling time for the 
325 ballasted flocs was much shorter (3 seconds) compared to non-ballasted flocs due to the 326 incorporation of sand that caused the premature flocs to become heavy and settle quickly. 327 However, the turbidity removal efficiency was slightly compromised due to presence of lesser 328 suspended flocs to enmesh the residual turbidity during sweep coagulation stage. The impact of 329 ballasting agent on the flocs formation and impurities removal is worth further investigation for 330 other different coagulation-flocculation mechanisms with different types of coagulants and 331 flocculants.

\section{Acknowledgements}

The authors would like to thank the Royal Society for funding this work through Royal Society International Collaboration Award (IC160133) (acknowledged under the grant code KK2017-006 at Universiti Kebangsaan Malaysia). The Malaysian authors would also express their gratitude to Dana Impak Perdana (DIP-2016-031) for the funding to this research.

\section{References}

341 [1] E. Y. Y. Chan and J. Y. Ho, Urban Water and Health Issues in Hong Kong, Urban Drought. 342 (2019) 241-262.

343 [2] P. N. Cheremisinoff, Handbook of water and wastewater treatment technology. 53 (2019).

344 [3] A. Matilainen, M. Vepsäläinen, and M. Sillanpää, Natural organic matter removal by coagulation during drinking water treatment: A review, Advance Colloid Interface Science. 159 (2010) 189-197.

350 [5] S. J. Randtke, M. B. Horsley, Water Treatment Plant Design, McGraw-Hill, New York, 3512012.

352 [6] W. L. Ang, A. W. Mohammad, Y. H. Teow, A. Benamor, and N. Hilal, Hybrid chitosan/FeCl3 coagulation-membrane processes: performance evaluation and membrane fouling study in removing natural organic matter, Separation and Purification Technology. 152 (2015) 23-31. 
[7] H. Zemmouri, M. Drouiche, A. Sayeh, H. Lounici, and N. Mameri, Coagulation Flocculation Test of Keddara’s Water Dam Using Chitosan and Sulfate Aluminium, Procedia Engineering. 33 (2012) 254-260.

[8] S. Kumar, N. C. Ghosh, and A. A. Kazmi, Ballasted sand flocculation for water, wastewater and CSO treatment, Environ. Technol. Rev., 5 (2016) 57-67.

[9] J. Jacobsen and S.-N. Hong, Microsand ballasted flocculation and clarification for the high rate treatment of storm waters and sewer overflow, Proceedings of the Water Environment Federation, 2002 (2002) 1966-1979.

[10] M. Lapointe and B. Barbeau, Characterization of ballasted flocs in water treatment using microscopy, Water Research. 90 (2016) 119-127.

[11] C. Desjardins, B. Koudjonou, and R. Desjardins, Laboratory study of ballasted flocculation, Water Research. 36 (2002) 744-754.

[12] J. Sieliechi, B. Lartiges, S. Skali-Lami, J. Kayem, and R. Kamga, Floc compaction during ballasted aggregation, Water Research. 105 (2016) 361-369.

[13] A. V. Ghanem, J. C. Young, and F. G. Edwards, Mechanisms of ballasted floc formation, Journal of Environment Engineering. 133 (2007) 271-277.

[14] J. C. Young and F. G. Edwards, Factors affecting ballasted flocculation reactions, Water Environment Research. 75 (2003) 263-72.

[15] H. Chaitra, H. B. Aravind, A. Senapati, Removal of total suspended solids and turbidity by ACTIFLO process using microsand, International Journal of Research in Engineering and Technology. 6 (2017) 138-144.

[16] V. Plum, C. P. Dahl, L. Bensten, C. R. Petersen, L. Napstjert, and N. B. Thomsen, The Actiflo Method, Water Science Technology. 37 (1998) 269-275.

[17] J. Gasperi, B. Laborie, and V. Rocher, Treatment of combined sewer overflows by ballasted flocculation: removal study of a large broad spectrum of pollutants, Chemical Engineering Journal. 211-212 (2012) 293-301.

[18] Y. Hwang, M. Maeng, and S. Dockko, Development of a hybrid system for advanced wastewater treatment using high-rate settling and a flotation system with ballasted media, International Biodeterioration and Biodegradation. 113 (2016) 256-261.

[19] L. de Magalhães, N. P. Noyma, L. L. Furtado, M. Mucci, F. van Oosterhout, V. L. Huszar, M. M. Marinho, and M. Lürling, Efficacy of Coagulants and Ballast Compounds in 
Removal of Cyanobacteria (Microcystis) from Water of the Tropical Lagoon Jacarepaguá (Rio de Janeiro, Brazil), Estuaries and Coasts. 40 (2017) 121-133.

[20] W. Zhu, R. Seth, and J. Lalman, Evaluation of a micro carrier weighted coagulation flocculation process for the treatment of combined sewer overflow, Environmental Technology. 28 (2007) 761-770.

[21] J. Wang, J. Guan, S. R. Santiwong, and T. David Waite, Characterization of floc size and structure under different monomer and polymer coagulants on microfiltration membrane fouling, Journal of Membrane Science. 321(2008) 132-138.

[22] W. L. Ang, A. W. Mohammad, A. Benamor, and N. Hilal, Hybrid coagulation-NF membrane processes for brackish water treatment: effect of $\mathrm{pH}$ and salt/calcium concentration, Desalination. 390 (2016) 25-32.

[23] M. Mikola and J. Tanskanen, Preparation and coagulation performance of solid aluminium formate, Journal of Water Process Engineering. 5 (2015) 1-5.

[24] M. I. Aguilar, J. Saez, M. Llorens, A. Soler, and J. F. Ortuno, Nutrient removal and sludge production in the coagulation-flocculation process, Water Research. 36 (2002) 2910-2919.

[25] S. Bhatia, Z. Othman, and A. L. Ahmad, Coagulation-flocculation process for POME treatment using Moringa oleifera seeds extract: optimization studies, Chemical Engineering Journal. 133 (2007) 205-212.

[26] Q. He, C. Deng, Y. Xu, D. Shen, B. Dong, and X. Dai, Optimization of and mechanism for the coagulation-flocculation of oil-field wastewater from polymer flooding, Desalination and Water Treatment. 57 (2016) 1-10.

[27] S. C. Kim, Application of response surface method as an experimental design to optimize coagulation-flocculation process for pre-treating paper wastewater, Journal of Industrial and Engineering Chemistry. 38 (2016) 93-102.

[28] P. Mpofu, J. Addai-Mensah, and J. Ralston, Investigation of the effect of polymer structure type on flocculation, rheology and dewatering behaviour of kaolinite dispersions, International Journal of Mineral Processing. 71 (2003) 247-268.

[29] A. Ghanem, J. Young, and F. Edwards, Settling velocity models applied to ballasted flocs a review, SABER. 25 (2013) 247-253.

[30] F. Roselet, D. Vandamme, M. Roselet, K. Muylaert, and P. C. Abreu, Screening of commercial natural and synthetic cationic polymers for flocculation of freshwater and 
marine microalgae and effects of molecular weight and charge density, Algal Research. 10 (2015) 183-188.

420 [31] J. Duan, J. Wang, T. Guo, and J. Gregory, Zeta potentials and sizes of aluminum salt 421 precipitates - Effect of anions and organics and implications for coagulation mechanisms, $422 \quad$ Journal of Water Process Engineering. 4 (2014) 224-232.

423

424

425

426

427 
The authors declare no conflict of interest. 